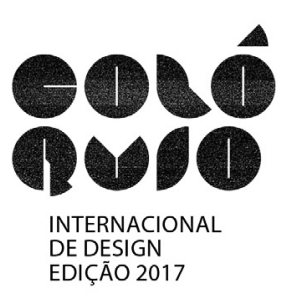

\title{
Design com Foco em Industrianato sob Abordagem Sistêmica
}

\author{
Giovana de Freitas Rabelo Ribeiro; \\ Luiz Fernando Goncalves De Figueiredo; \\ Eliete Auxiliadora Assunção Ourives
}

\section{Resumo:}

A população brasileira é formada por uma sociedade de culturas diferentes que se instalaram em regiões com características próprias gerando um artesanato diversificado e regionalista, e o design que, "para Walter Gropius, fundador da Bauhaus, esta concepção de arte e artesanato devia ser considerada não a partir da perspectiva de duas atividades, mas como dois ramos da mesma atividade" (Mozota, 2011, p.37), sempre foram indiferentes evitando a aproximação com o artesão, até que nos anos de 1980, houve uma busca da revitalização do artesanato através da preservação das técnicas produtiva. Esta parceria gerou um avanço, mas também pontos de tensão, que promoveu uma reflexão visando o desenvolvimento de um processo adequado. Em 1995 surge o PAB/MDIC - Programa de Artesanato Brasileiro do Ministério de Desenvolvimento, Indústria e Comércio, com as informações do SICAB - Sistema de Informação Cadastrais do Artesanato Brasileiro, com o intuito de elaborar políticas públicas, e planejamento de ações de fomento para o setor artesanal. A investigação inicia a discussão sob uma abordagem sistêmica e a gestão de design, que é uma forma de organizar e gerenciar o tema artesanato, suas classificações, suas formas tradicionais de trabalho e a relação com o processo industrial. Através dos conceitos que permeiam o tema, uma análise do artesanato como uma atividade produtiva e geradora de renda, e diante da importância deste setor e de seu grande desenvolvimento torna-se necessário propor uma classificação dos produtos a partir de inovações de processos, aplicação de gestão e qualificação do artesão. Dentro deste contexto e levando em consideração a necessidade de realizar pesquisas acadêmicas sobre o artesanato, surge à indagação de como a produção do artesanato em larga escala se relaciona com os processos produtivos, a gestão e a indústria e o que pode ser denominado industrianato. A pesquisa classifica-se em sua natureza como básica já que objetiva gerar novos conhecimentos para o avanço da ciência sem aplicação prática prevista, em relação à forma de abordagem como qualitativa, pois busca conhecimentos no mundo real, não podendo ser traduzido em números, segundo os seus objetivos como exploratória visto que objetiva proporcionar maior familiaridade com o problema por meio de uma pesquisa teórico-bibliográfica sobre artesanato e industrianato. 0 resultado da busca através dos conceitos e pesquisas encontradas permitiu desenvolver uma reflexão sobre a conceituação de industrianato existente mostrando que pode ser ampliado e melhor classificado. Os produtos resultantes de um artesanato onde se aplica a gestão de design sob uma abordagem sistêmica pode utilizar ou classificar o industrianato.

Palavras-chave: Gestão de Design; Artesanato; Indústria; Inovação de Processos. 


\section{Introdução}

$\mathrm{O}$ artesanato iniciou junto com a história da humanidade tendo seus primeiros objetos catalogados no período Neolítico. Com a evolução o homem precisou desenvolver armas para caça e objetos/utensílios para atender às suas crescentes necessidades. No Brasil o artesanato é uma atividade que está associada a tradições indígenas, e ao processo de colonização, provenientes de técnicas passadas de geração para geração, sendo perceptível a sua importância no ambiente social, econômico e cultural. Conforme descrito nas enciclopédias, e segundo ditos populares a expressão "artesanato", que surgiu em fins do século XIX, refere-se ao trabalho manual feito pelo artesão onde ele possui seus próprios meios de produção, realiza todas as etapas da produção, desde a extração da matéria-prima até a comercialização, de maneira individual ou colaborativa, podendo também ser de base comunitária ou familiar. (SANTIAGO, 2014)

Com o intuito de contribuir para ampliar os conhecimentos sobre a atual classificação do artesanato no Brasil e com o objetivo geral de buscar a compreensão conceitual do industrianato, por meio da abordagem sistêmica, tendo como base os conceitos de gestão, design, artesanato e indústria através dos objetivos específicos de pesquisar os conceitos de abordagem sistêmica, gestão, design, gestão de design, artesanato, indústria e inovação, analisaremos a relação dos conceitos para a conceituação do industrianato. De natureza básica, abordagem qualitativa, exploratória, buscou-se familiaridade com o problema através de levantamento teórico-bibliográfico e das conceituações relacionadas. Pretende-se compreender as conceituações e as relações entre elas objetivando uma clareza das posições de cada agente envolvido no sistema apresentado objetivando uma definição coerente de industrianato.

Observou-se que o industrianato apenas classifica o artesanato "souvenir" produzido em larga escala com foco no mercado turístico. Neste conceito podemos agregar outros tipos de produções artesanais que atuam com interferência do design, dentro de uma abordagem sistêmica, com inovação nos processos gerando uma produção semi-industrial.

\section{Fundamentação Teórica}

Para buscar a conceituação de Industrianato se faz necessário abordar alguns conceitos e suas relações com o termo proposto neste trabalho, visando construir uma discussão.

\subsection{Design}

O design moderno nasceu na Alemanha em 1919, com o aparecimento da Escola Bauhaus e seus movimentos de ideias que combinavam aulas teóricas fundamentais com trabalhos práticos nas oficinas, valorizando a arte e o artesanato. Em 1930, em meio à crise econômica o designer torna-se profissão nos Estados Unidos, e no Brasil, só em 1940 o processo de formação de designers e de um campo de atuação efetivamente atuante na produção de bens industriais se intensificou. (MORAIS, 2014).

Termo utilizado muitas vezes de forma incorreta, associado apenas à forma ou visual inovador, a palavra "design" deriva do termo latim designare, traduzido como "designar" e "desenhar". "No inglês o substantivo "design" tem vários significados: projeto, plano, intenção, processo" ou "modelo, esboço, decoração, composição visual, estilo". O design agrega muito mais do que mera forma estética, ele incorpora aspectos funcionais, ergonômicos, tecnológicos e de produção, visando atender as necessidades do usuário. Muitos conceitos surgiram, dentre eles Mozota apresenta o design como uma atividade que concebe sinais, espaços, ou artefatos para satisfazer as necessidades específicas, de acordo com um processo lógico da abordagem científica e as dimensões intuitivas e artísticas do trabalho criativo. O ICSID (International Council of Societies of Industrial Design) conselho internacional mais representativo que promove e protege os interesses do profissional, tem como definição:

"uma atividade criativa cuja finalidade é estabelecer as qualidades multifacetadas de objetos, processos, serviços e seus sistemas em ciclos de vida inteiro. Portanto, design 
é o fator central da humanização inovadora de tecnologias e o fator crucial de intercâmbio cultural e econômico". (ICSID, 2012)

Atividade projetual criativa, o design se torna o solucionador dos problemas do usuário, do artefato e do sistema, em uma metodologia flexível dividida em etapas, identificando problemas, gerando soluções até a condução do resultado final, ele valoriza a estética do produto para atrair o cliente, através da valorização dos signos e significados além de se preocupar com a busca de novas soluções que equilibrem o desejo humano com a economia, viabilidade técnica e a sustentabilidade. (BELCHIOR, 2014).

Por volta de 1980 surge um movimento de aproximação do designer com o artesão em busca da revitalização do produto visto que o artesanato vinha ocupando um grande espaço no cenário globalizado e visando imprimir aspectos materiais e imateriais nos produtos. A parceria designer/artesão pode gerar ações e estratégias que potencialize o desenvolvimento econômico e social com a preocupação de manter as tradições, a cultura local e o processo de criação do artesão. Inicia-se uma mudança que posteriormente pretendemos chamar "industrianato". Para atingir estes objetivos temos de entender a gestão.

\subsection{Gestão}

O termo gestão possui sinônimo como administração e gerenciamento. Visando entender seu funcionamento para a utilização em projetos de design, começamos na primeira revolução industrial com a descoberta da máquina a vapor e a segunda com o surgimento da energia elétrica, gerando um surto de crescimento e progresso. Com isto novos processos industriais começaram aparecer visando à produção mais rápida e o menor custo. Com o intuito de organizar estas novas empresas, duas correntes formaram o modelo global de gestão: A Administração Científica - Com foco nas tarefas dos operários, consistia em eliminar o desperdício; e a Teoria Clássica da Administração - Com ênfase na estrutura organizacional, possui abordagem sintética, global e universal, com uma visão anatômica e estrutural da empresa. (MARTINS, 2011).

A gestão através de um modelo plano e flexível do final do séc. XX, que valoriza a criatividade, a iniciativa, o cuidado com os detalhes e a preocupação com o cliente, é inserido de forma gradativa, responsável e deliberado nos projetos de design. Segundo Mozota, o campo do design tem afinidade com a gestão que é uma ferramenta de resolução de problemas e pode ser integrado com os outros processos da organização, onde a diferenciação começa com um briefing, que define a natureza do problema a ser resolvido e integra uma pesquisa de mercado, estratégia de marketing, marca engenharia, desenvolvimento de um novo produto, planejamento da produção, distribuição e política de comunicação corporativa.

No artesanato a gestão proporcionada pelo design pode agregar valor ao produto além de atuar na colocação deste produto no mercado gerando maior fonte de renda e desenvolvimento. Neste contexto estaremos caminhando para uma produção "industrianato". A junção do design e a gestão visando uma abordagem sistêmica do processo gerou a gestão de design que veremos abaixo.

\subsection{Gestão de Design}

O processo de criação, de decisão e de escolhas é o novo comércio intelectual das culturas, e a necessidade do designer como integrador deste processo fez surgir, nos anos 60, na Inglaterra, a Gestão de Design, com a missão de assegurar a condução eficaz do projeto e a comunicação entre o escritório e seu cliente. (MARTINS, 2011). Gorb (1990) traz a definição de que a Gestão de Design diz respeito a eficaz aplicação dos recursos de design pelos gerentes para atingir os objetivos estratégicos. Após uma década, Avendaño, propõe:

"Gestão de design como o conjunto de atividades de diagnóstico, coordenação, negociação e design que se leva a cabo tanto na atividade de consultoria externa como no âmbito da organização empresarial, interagindo com os setores responsáveis pela produção, programação, setor econômico, financeiro e da comercialização, com a finalidade de permitir uma participação ativa do design nas decisões dos produtos" (AVENDAÑO, 2002, p.40). 
Para o DMI (2013) a Gestão de Design abrange os processos, as decisões de negócios e estratégias que permitem inovar e criar produtos, serviços, comunicações, ambientes e marcas projetados de forma eficaz que melhoram a qualidade de vida e proporcionam o sucesso organizacional. De acordo com Mozota (2011, p.95) "uma característica diferenciadora da gestão do design é o seu papel na identificação da comunicação de maneiras pelas quais o design pode contribuir com o valor estratégico de uma empresa". Para Martins, "é um conjunto de técnicas de gestão dirigido a maximizar, ao menor custo possível, a competitividade [...] utilizando do design como instrumento de sua estratégia empresarial". (Martins, 2011, p.13). Resumindo, é função do designer, organizar e compreender integrando ideias, projetos e processos em todos os setores da empresa, de forma sistêmica atuando nos três níveis, segundo Mozota, estratégico, tático/funcional e operacional. Onde o nível estratégico trata da visão de design, atuando na gestão do conhecimento dentro do ambiente empresarial, entendendo o produto e transformando procedimentos; o nível tático trata a função do design, envolve estrutura, tecnologia, inovação, atuando sobre as pessoas, ajudando a incentivar e mobilizar a equipe; e o nível operacional trata a ação de design envolvendo marketing, produção e comunicação, se refere aos processos e projetos, documentação, controle e implementação das soluções. (LAURO, 2014)

Neste contexto a parceria design/artesão conta com a qualificação do design para conquistar um mercado globalizado, podendo analisar o negócio de forma integrada buscando melhoria e agregando valor ao produto.

\subsection{Abordagem Sistêmica do Design}

$\mathrm{Na}$ ciência do século XX, a perspectiva holística ficou conhecida como "sistêmica", e a maneira de pensar passou a ser conhecida como "pensamento sistêmico, contextual ou ambientalista" onde as propriedades das partes podem ser entendidas apenas a partir da organização do todo, o que significa um "todo" mais amplo onde as relações são fundamentais, embutidas em redes. (CAPRA). Para Bertalanffy, abordagem sistêmica é o estudo global dos sistemas de forma a envolver todas as suas interdependências, já que cada um dos elementos, ao serem reunidos para construir uma unidade funcional maior, desenvolvem qualidades que não se encontram em seus componentes isolados" (BERTALANFFY, 2008). Morin (2005) complementa dizendo que este novo olhar enfatiza as unidades complexas ao invés das unidades simples; em vez dos agregados formando corpos, os sistemas de sistemas. Estes sistemas podem ser fechados, quando não se comunicam com o meio ambiente e abertos quando sofrem influência do ambiente ou recebem recursos externos.

A necessidade do design se interagir com o ciclo de vida do sistema-produto, pré-produção, produção, distribuição, uso e descarte, além de conhecer a inter-relação entre as partes e seu entorno, assume uma abordagem sistêmica, a prática projetual (MANZINI, 2005). Pode ser considerada mais que um sistema relacionado à estratégia e administração empresarial, pois esta também atua na sua motivação pessoal e profissional, bem como, nos colaboradores do processo, e ainda têm capacidade de influência sobre o usuário. Estas inter-relações entre os projetos e os profissionais de design são necessárias para o desenvolvimento de um produto/serviço, mostrando que a diversidade dos profissionais aliada à integração com outros tipos de atividades, como engenharia, artes, administração entre outros, é capaz de formar um sistema. Sendo assim, o foco seria o processo de interação entre as partes que constituem uma estrutura, não ocasionando um deslocamento da ênfase do todo.

"o design caminha para uma nova configuração, na qual projetos de forma isolada e apenas operacionais vêm perdendo espaço para projetos sistêmicos e estratégicos visto pelos seus resultados como importantes avanços para as organizações". (Martins, 2011, p.227)

No âmbito da parceria design/artesão a abordagem sistêmica através da concepção de produtos, serviços, processos e sistemas podem contribuir através das técnicas de mapa mental, mapa conceitual, diagramas e fluxogramas para desenvolver habilidades, conceitos, ideias, informações, ajudar na compreensão e desbloquear a inovação. 


\subsection{Indústria}

O termo se refere á criação de um sistema de fabricação através da mecanização, aumentando a produtividade e reduzindo custos. (Cardoso, 2004). A palavra indústria segundo o dicionário Aurélio,

"S.f. 1. Destreza ou arte na execução de um trabalho manual; aptidão; perícia. 2. Profissão mecânica ou mercantil; ofício. 3. Econ. A atividade secundária da economia, que engloba as atividades de produção ou qualquer dos seus ramos, em contraposição às atividades agrícolas (primárias) e a prestação de serviços (terciárias). 4. Econ. Conjugação do trabalho e do capital para transformar a matéria prima em bens de produção e consumo. 5 . O conjunto das empresas industriais; o complexo industrial

O surgimento da máquina a vapor deflagrou muitas revoluções na história da humanidade, as chamadas Revoluções Burguesas do Séc. XVIII, responsável pela crise do antigo regime capitalista comercial para o industrial propiciando um espetacular desenvolvimento na Inglaterra, França, Alemanha e Estados Unidos. (ABIMAQ). Uma rápida expansão da mecanização observou-se juntamente com um conjunto de fatores sociais, culturais e ideológicos gerando uma profunda transformação conhecida como revolução industrial. Inicialmente na Inglaterra e posteriormente na França, Estados Unidos e outros países com menor intensidade como o Brasil, grandes fábricas foram tomando o lugar das oficinas gerando mudanças na organização do trabalho, da produção e da distribuição visando aumentar o volume de produtos para atender o aumento do consumo. (Cardoso, 2004). Outros momentos de desenvolvimento rápido industrial foram à invenção da produção em série com as máquinas automáticas de Henry Ford e posteriormente na Segunda Guerra Mundial à criação da primeira máquina computadorizada que evoluiu para o nosso computador. (ABIMAQ).

A participação da indústria de pequeno porte para executar parte da produção artesanal é crescente a partir do momento que o mercado se torna globalizado e o artesão necessita rever seu fazer manual visando aumentar a produção e agregar valor aos produtos. Novos processos de produção através da adoção de novas tecnologias, decorrentes das inovações que têm sido implementadas na parceria artesão/design.

\subsection{Inovação}

A liberdade de pensar de forma criativa, o estímulo á troca de ideias, o espírito colaborativo, determinam uma cultura criativa na empresa.

"Em uma empresa com a cultura criativa bem desenvolvida, ninguém fala a respeito desta cultura, pois a inovação está no DNA da empresa, codificada em seu comportamento; a inovação avança continuamente e em todas as direções". (THAÍS, 2011, p. 291).

$\mathrm{O}$ conceito de inovação está vinculado ao interesse de quem define, relacionadas à ciência e tecnologia, como por exemplo, temos mudanças de processos, equipamentos, comportamento com mudanças de atitudes e habilidades das pessoas; relação homem-máquina ou máquina-máquina; empreendimento com mudanças no produto, serviço, mercado, negócios, etc. (MAÑAS, 2001). "A inovação é um processo coletivo e interativo que está próximo da realidade do processo de design, uma vez que combina fatores internos e externos" (MOZOTA, 2011, p.146).

Há três tipos de inovação: marginal ou incremental, radical ou disruptiva e semirradical, dependendo do grau de transformação no modelo de negócio e o uso de novas tecnologias. Na marginal temos um menor risco e um menor investimento, a radical um maior risco e maior investimento e a semirradical por sua vez, um risco e investimento intermediário. (THAÍS, 2011). Podemos também classificar o processo de inovação quanto ao nível que a empresa quer inovar, de acordo com Thaís (2011), estes níveis são quatro: Inovação de modelo de negócio; Inovação de processo; Inovação de mercado; Inovação de produtos e serviços.

Podendo ser implantado passo a passo em cada nível, ao invés da versão radical, o que torna um negócio sustentável. 
Quanto ao processo de inovação podemos citar o descrito por Fonseca (1998), o qual possui quatro etapas específicas para produtos, mas que podem ser adaptadas para serviços e estratégias. São elas:

- Desenvolvimento do conceito (definição do potencial de mercado, orçamento financeiro, competidores potenciais, viabilidade técnica e implicações industriais);

- Planejamento do desenvolvimento do produto (identificação dos departamentos envolvidos, contribuições interdisciplinares, modelo de comunicação entre envolvidos, desenvolvimento de cronograma);

- Desenvolvimento (ciclos do design, prototipagem e construção de modelos, envolvendo os clientes);

- Início da produção piloto (negociação referente a problemas existentes).

No artesanato a inovação é implícita, e os processos vão se desenvolvendo de acordo com as necessidades sem muitas técnicas ou métodos, podendo agregar recursos industriais visando aumentar a produtividade. Este desenvolvimento descentraliza a produção e transforma o artesanato no que estamos buscando como definição "industrianato", porém, o Sebrae o conceitua para "souvenir" as pequenas lembranças desenvolvidas por artesão com utilização de moldes, formas, máquinas e equipamentos visando atender a turistas.

\subsection{Artesanato}

No Brasil o artesanato é uma atividade que está associada a tradições indígenas, e ao processo de colonização, provenientes de técnicas passadas de geração para geração, sendo perceptível a sua importância no ambiente social, econômico e cultural, apesar de não fazer parte das políticas públicas até meados dos anos 80. As pessoas com habilidades que eram responsáveis por toda produção chamou-se artífices/artesão.

"O artesanato é um dos meios mais importantes de representação da identidade de um povo. Através dele não só os materiais e as técnicas, mas também os valores coletivos são fortemente representados."[...] Historicamente ligadas a aproveitamento de materiais locais, e à reciclagem, muito antes que estas noções estivessem difundidas na sociedade como um todo.[....] a produção artesanal está sintonizada com a noção contemporânea de sustentabilidade, que compreende os conceitos de ambientalmente responsável, economicamente inclusivo e socialmente justo." (BORGES, 2011, p. 217)

Caracterizando-se por qualificação não formal, maior liberdade de ação, ferramentas simples, matérias-primas locais, técnicas tradicionais [...] estimula e fortalece a autoestima ao ser uma atividade que exige habilidade, destreza e criatividade. (SERAFIM, 2015, p.15)

Uma característica do processo de produção artesanal é a baixa produtividade devido à forma manual que cada objeto é produzido, com isto cada peça tem sua identidade cultural e local, particularidade, singularidade e exclusividade. Com o Crescimento, a evolução da sociedade e a mecanização dos processos a produção artesanal passa a ser entendida como uma forma alternativa de produção, rompendo a relação criação/projetação/produção centralizada em uma única pessoa. Nesta "semi-industrialização" as etapas de produção são desenvolvidas por operários e artesãos distintos, o que torna o processo mais ágil e produtivo. A partir de então é importante a definição de conceitos, diretrizes, metas e estabelecimento de estrutura organizacional visando contribuir para o desenvolvimento do artesanato de forma integrada. (SEBRAE, 2010).

Os artesãos não estão numa redoma, imunes a qualquer influência exterior. Em interação com o mundo à sua volta, estão se transformando continuamente e, muitas vezes, transformando o seu próprio trabalho. Decidir, desde uma visão de fora, preservar algo a qualquer custo pode ser considerado uma espécie de condecoração à imobilidade e, portanto, à morte. (BORGES, 2011, p.138). 
Muitas conceituações foram utilizadas para classificar o artesanato até que o Ministério do Desenvolvimento Indústria e Comércio coordenou o projeto nomeado Programa do Artesanato Brasileiro, em parceria com o Sebrae, classificando e valorizando diversas categorias em cada região do Brasil de acordo com suas particularidades. No decreto 7096, do artigo 23, no anexo I de quatro de fevereiro de 2010 temos as conceituações para padronizar e estabelecer os parâmetros do Programa Artesanato Brasileiro (PAB), revisado em 15 de março de 2012 especifica o conceito básico de artesanato e o artesão conforme abaixo:

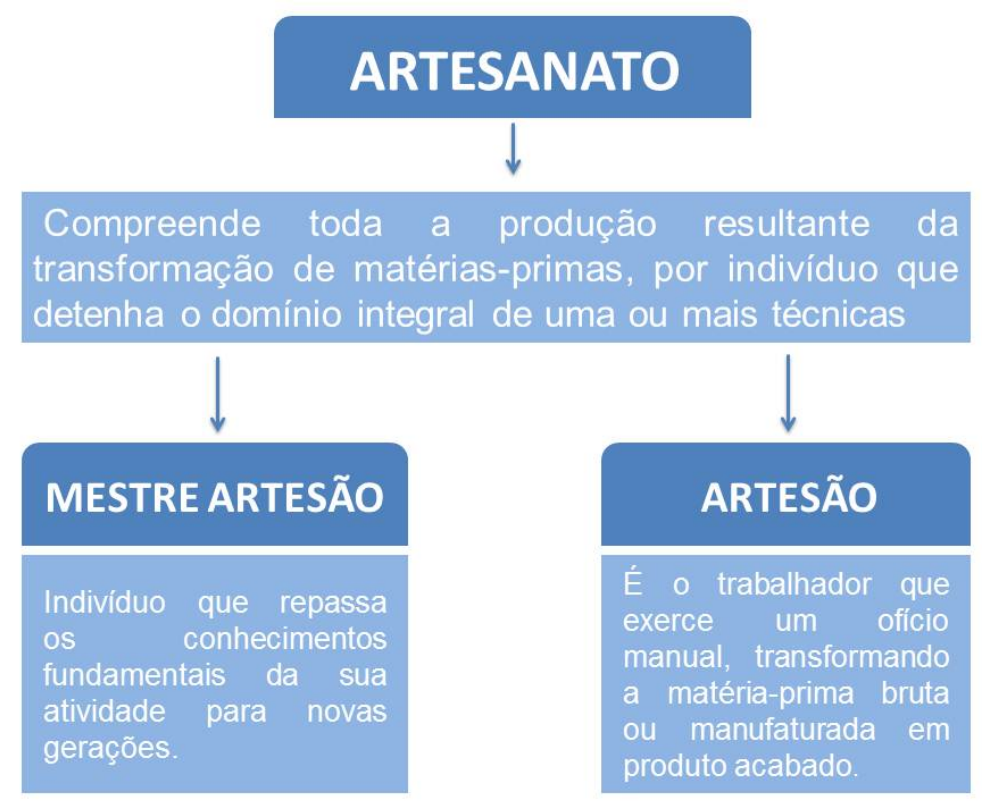

Figura 1 - Autor

As classificações dos tipos de artesanato foram também definidas conforme a origem, a natureza da criação, o modo de produção, quem produz, e o que o produto representa. Assim temos na figura 2:

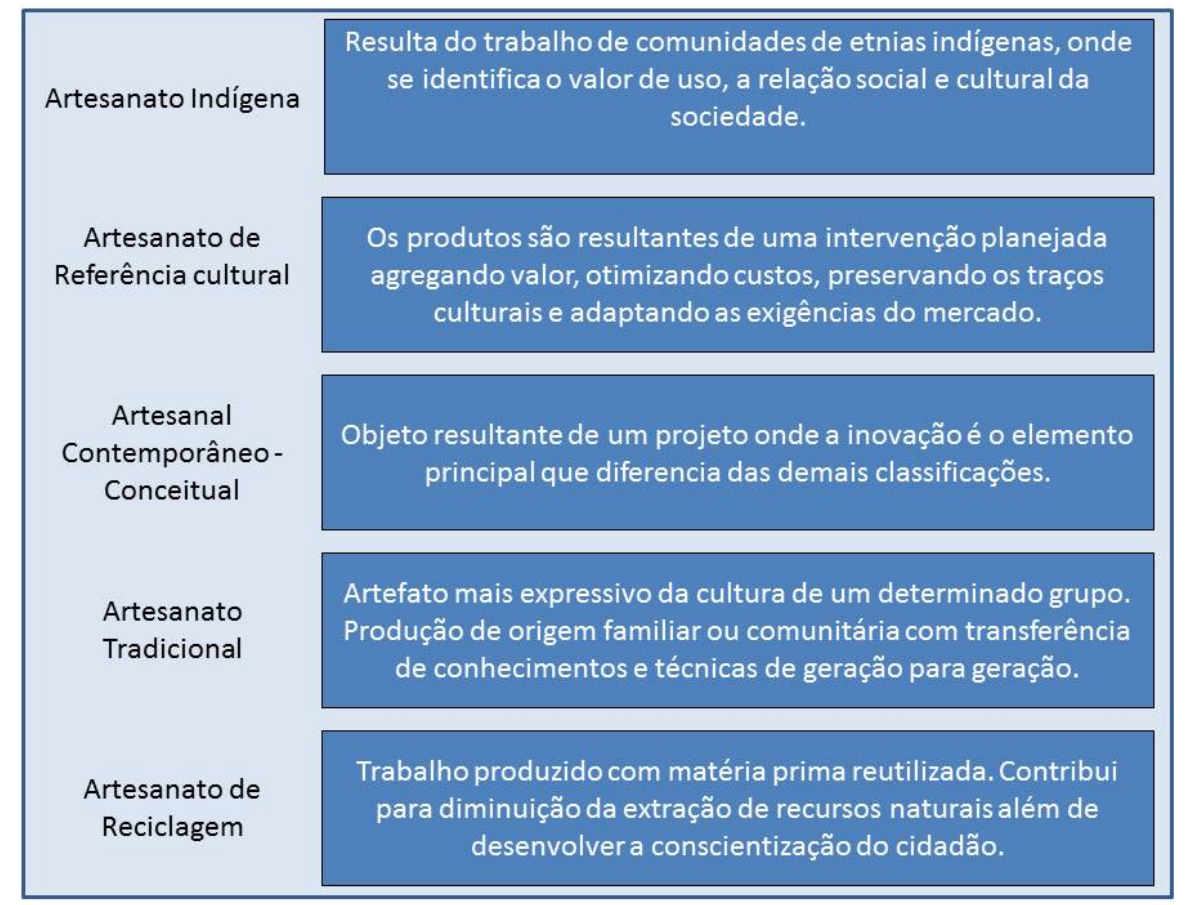

Figura 2 - Autor 
Observamos que o artesanato de referência cultural e o artesanato conceitual tem a intervenção externa com uma visão de mercado, podendo ser utilizado processos industriais ou semi-industriais e aplicado uma gestão de design. Apesar de não serem citadas, estas características podem enquadrar como um "industrianato". A produção pode ser classificada conforme figura 3 abaixo:

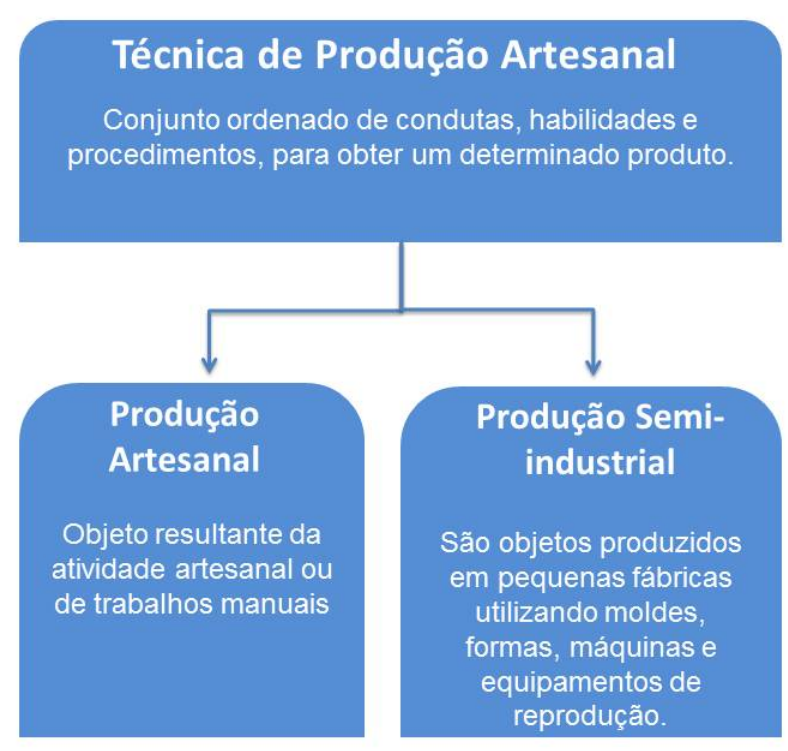

Figura 3 - Autor

"Há vários indícios, ao contrário, de que o lugar do artesanato na sociedade contemporânea está se expandindo. Este crescimento se lastreia não mais meramente na capacidade dos objetos atenderem a sua função, mas na sua dimensão simbólica”. (BORGES, 2011, p.203). É neste contexto que buscamos resposta para a conceituação de Industrianato.

\subsection{Industrianato}

Conforme os conceitos propostos anteriormente, entendemos que ao longo do desenvolvimento do artesanato, os propósitos, as técnicas, ferramentas e equipamentos, processos e objetivos dos artesãos foram modificando e várias ramificações do artesanato foram surgindo. Sem o controle total da estrutura operacional, ou utilizando apenas o saber passado de geração para geração a classificação de "artesanato" foi se perdendo e deu espaço a uma estrutura que poderá ser classificada "industrianato", onde o processo produtivo é manual e industrial. De acordo com estudos acadêmicos levantados, este termo vem sendo utilizado como classificação do Sebrae, em citações, sem nenhuma pesquisa acadêmica encontrada. Vejamos:

Em 1984, Oliveira, P. S. caracteriza como sendo o industrianato uma produção de maior escala dominada pela informalidade de modelos e cores, visando atender as exigências do mercado.

Em 1994 Frade, Isabela Nascimento define souvenir/artesanato "de massa", industrianato as peças desenvolvidas pelo produtor que não está interessado em passar qualquer mensagem sociocultural a quem vai entrar em contato com o objeto; a preocupação dele está no comércio, visa exclusivamente o lucro. Para tal utiliza as mais diversas técnicas de produção em série, marketing/mídia para entender como os produtos podem ser mais lucrativos e atraentes economicamente.

Em 2001 Ludimila de Miranda Rodrigues, cita a Secretaria Nacional de Assuntos Institucionais-SNAI, que define como industrianato os objetos cuja matéria-prima é industrializada e sua produção é feita em série, utilizando, na maioria das vezes, moldes, formas ou máquinas. A criação pode ser direcionada por ondas temporárias de consumo. Sua cópia pode ser praticada, por não possuir identidades que garantam sua originalidade. Podem ser utilitários ou decorativos. 
No ano seguinte, 2002, Rabelo, Lívia define que a inclusão do artesanato no ramo de atividades econômicas levou a um processo de industrialização do produto artesanal, voltado para o consumo turístico também de massa o que denominou industrianato. Este produto feito em larga escala e distribuído para além do território de origem, desvinculando-se de uma localidade, tradição ou comunidade específica, entre outras características.

Já em 2006, Costa, Aline de Caldas define industrianato, o artesanato feito em larga escala e distribuído para além do território de origem, desvinculando-se de uma localidade, tradição ou comunidade específica, entre outras características.

Diante destas conceituações podemos concluir que o industrianato está focado na produção de "souvenir" e que como parte da produção sendo industrial poderia estar classificando outros tipos de produtos artesanais onde a implantação de processos de design, gestão de design, e inovação resultaria em produtos mais qualificados e competitivos para o mercado global. Uma atividade a ser citada como exemplo, é a produção moveleira através do design autoral, uma produção segmentada através de processos manuais e industriais objetivando produtos diferenciados, originais, verdadeiras obra de arte.

\section{Metodologia}

"Metodologia tem como função mostrar a você como andar no "caminho das pedras" da pesquisa, ajudá-lo a refletir e instigar um novo olhar sobre o mundo: um olhar curioso, indagativo e criativo". (Silva, 2005.). "Metodologia é o estudo dos métodos ligados à solução de problemas teóricos e práticos". "O conceito "método" deriva, etimologicamente, do grego-latino, e significa caminho para alguma coisa, seguir ou andar ao longo do caminho." (Merino, 2011, p.70). "A metodologia científica, originalmente devida a de Descartes, propõe chegar à verdade através da dúvida sistemática e da decomposição do problema em pequenas partes, características que definiram a base da pesquisa científica" (Lana, 2011, p.55).

O presente estudo de natureza básica, abordagem qualitativa, exploratória, buscou-se familiaridade com o problema através de levantamento teórico-bibliográfico. Um mapa mental que é a organização das principais palavras visa organizar, estimular o raciocínio e compreender as relações de forma sistemática e proporcionando uma visão holística. (Figura 4)

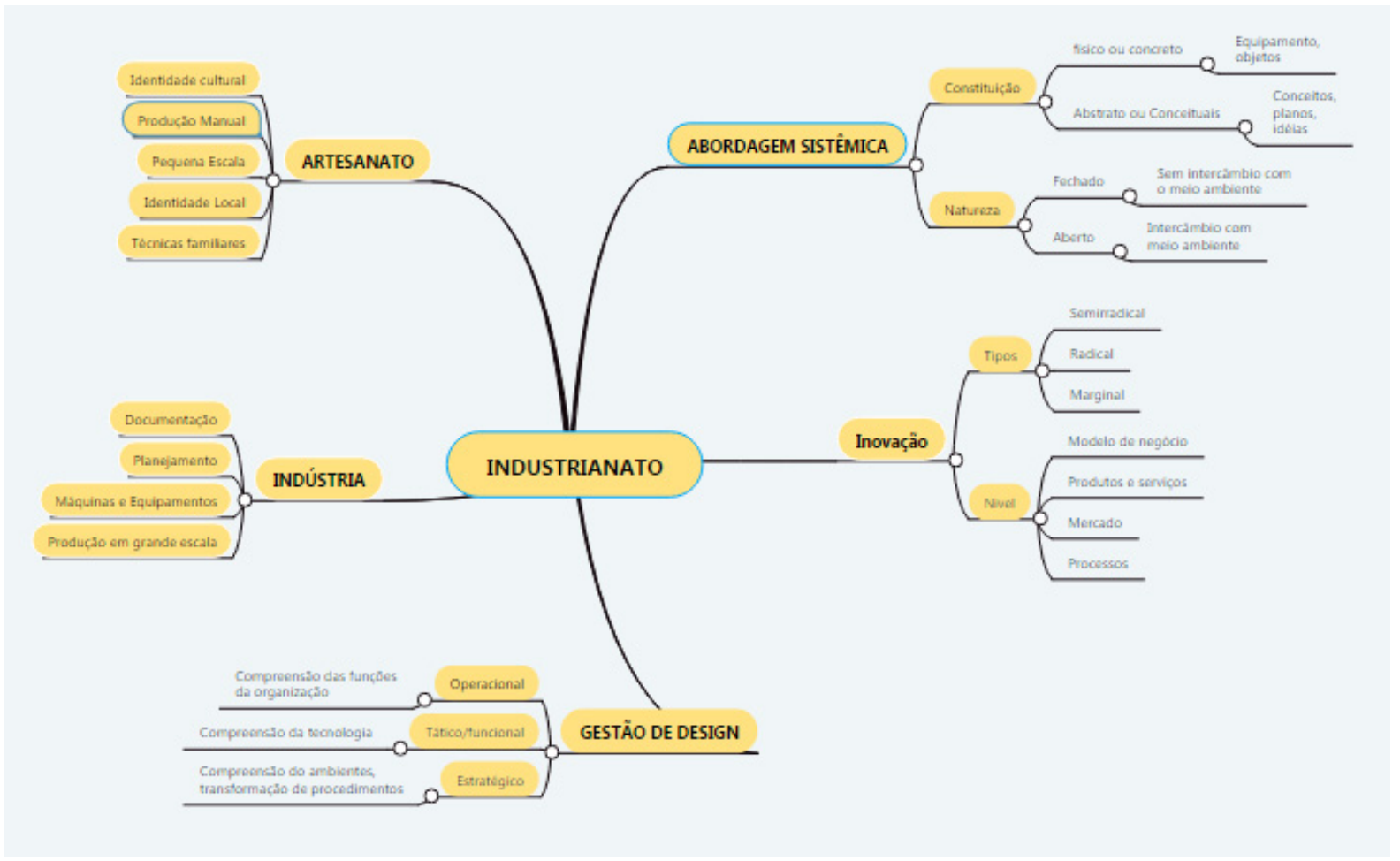

Figura 4-Autor 
Para um melhor entendimento dos conceitos e suas relações sistêmicas foi desenvolvido um mapa conceitual, rede hierárquica visando representar as informações de forma clara e resumida, facilitando o aprendizado do conteúdo e mostrando uma visão holística dos temas abordados e suas inter-relações. Conforme apresentado na figura 5.

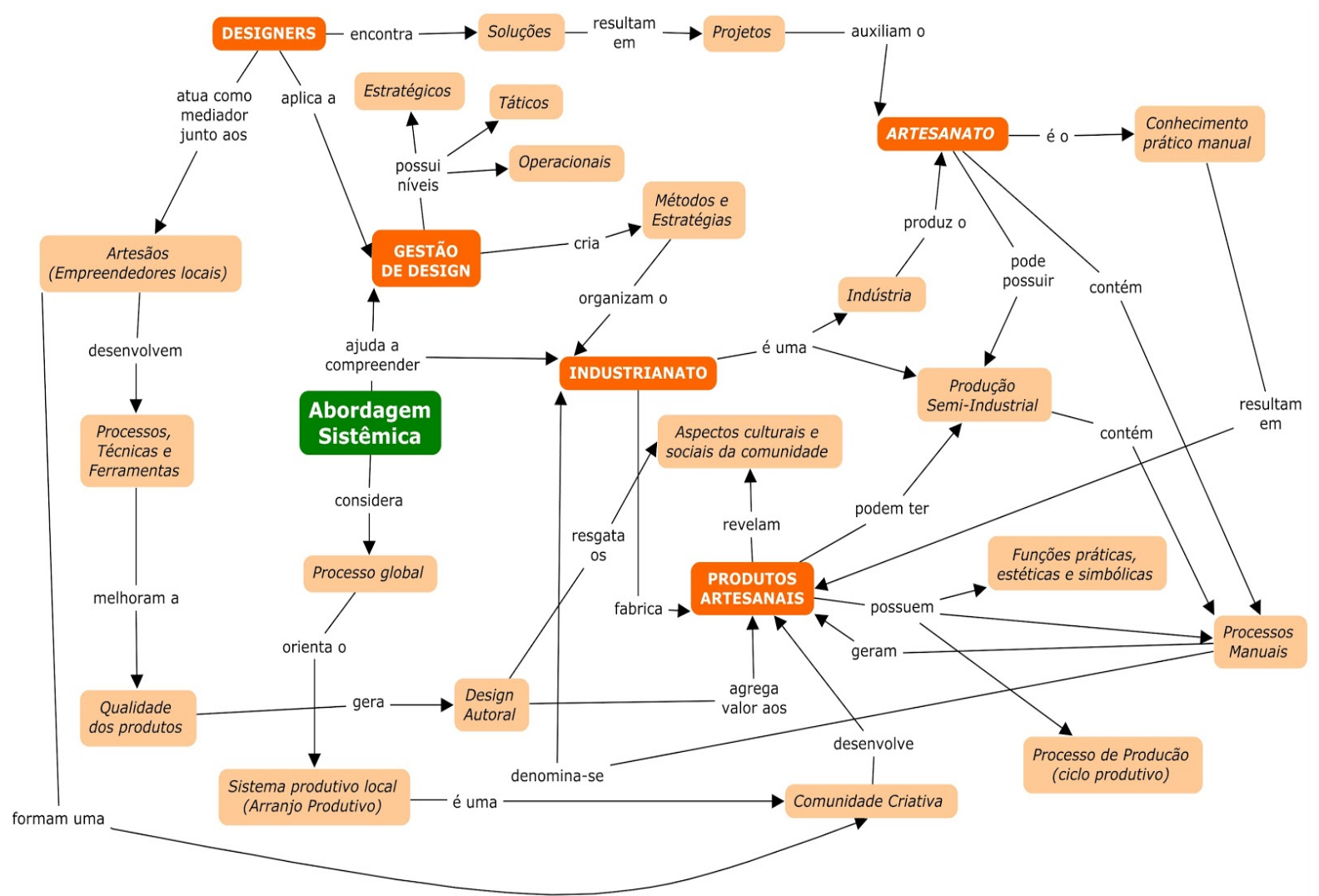

Figura 5 - Autor

Finalizando com um diagrama síntese e sistêmico para definir a estruturação do artigo de modo a conduzir a um melhor entendimento.

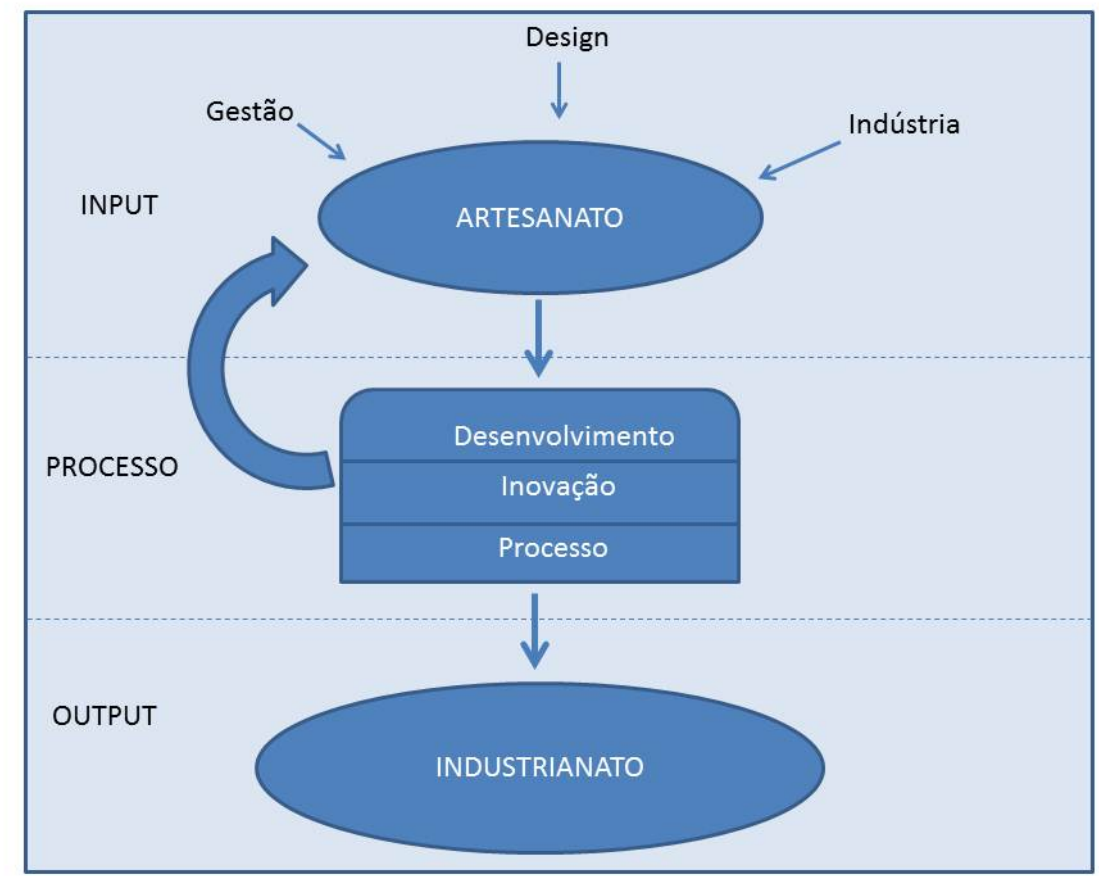

Figura 6 - Autor 


\section{Considerações Finais}

Depois de relacionar os conceitos de design, gestão, gestão de design, abordagem sistêmica, inovação e artesanato com o intuito de articular a conceituação de industrianato podemos estabelecer relações coerentes e eficientes entre design e o campo da gestão que analisado dentro de uma abordagem sistêmica caracteriza a gestão de design (figura 5). A gestão destes conceitos por um designer, junto ao artesanato potencializa a produção e desenvolve uma estratégia de inovação com a valorização da identidade cultural e local, além de adequar o produto ao mercado, capacitar os produtores e artesãos, apresentar valores estéticos e culturais despercebidos, introduzir processos, supervisionar qualidade, criando uma linha de produção e gerando um novo modelo de negócio. Será uma classificação para industrianato?

$\mathrm{O} \mathrm{PAB} / \mathrm{MDIC}$ conceitua:

"Artesanato de referência cultural: São produtos cuja característica é a incorporação de elementos culturais tradicionais da região onde são produzidos. São, em geral, resultantes de uma intervenção planejada de artistas e designers, em parceria com os artesãos, com o objetivo de diversificar os produtos, porém preservando seus traços culturais mais representativos". (Mascêne, 2010, p.14)

Artesanato conceitual: Objetos produzidos a partir de um projeto deliberado de afirmação de um estilo de vida ou afinidade cultural. A inovação é o elemento principal que distingue este artesanato das demais categorias. Por detrás desses produtos existe sempre uma proposta, uma afirmação sobre estilos de vida e de valores, muitas vezes explícitos por meio dos sistemas de promoção utilizados, sobretudo àqueles ligados ao movimento ecológico e naturalista. (Mascêne, 2010, p.14)

Produtos semi-industriais e industriais "Industrianato/ Souvenir" Produção em grande escala, em série, com utilização de moldes e formas, máquinas e equipamentos de reprodução, com pessoas envolvidas e conhecedoras apenas de partes do processo. Souvenir são objetos produzidos com foco no mercado turístico, que expressam identidade cultural, comunica conceitos e busca qualidade e funcionalidade das peças. (Mascêne, 2010, p.13)

Analisando estes conceitos verificamos uma necessidade de intervenção do design para que estes modelos sejam nomeados. Portanto podemos dizer que temos uma parceria artesão/design onde a implantação do processo de design, gestão de design, e inovação resulta em produtos com mais qualidade e mais competitivos no mercado globalizado, ampliando assim as características necessárias para instalar um industrianato.

\section{Design with focus on Industrianato under Systemic Approach}

\section{Abstract:}

The Brazilian population is formed by people of different cultures that have settled in regions with own characteristics by generating a diverse crafts and regionalist, and the design, according to Gropius, should be connected to the crafts, has always been indifferent while avoiding the approximation with the artisan, until in 1980, with the support of the Government there has been a paradigm breaks. The investigation starts a discussion on the crafts theme, and your relationship with the industry and design, under a systemic approach. In 1995 appears the PAB/MDIC having the purpose to create public policies, and after, a program of SEBRAE that enables the crafter to the entrepreneurship.

The investigation starts a discussion about a systemic approach and the design management, that is a way to organize and manage the craft topic, it's classifications, it's traditional technics of work and the relation with the industrial process. Throughout the concepts that are related to the topic, a craft analysis as a productive activity and profitable, and due to the importance of this sector and to it's major development, becomes necessary a classification of the products from process 
innovations, management application and crafter qualification. Within this context, and taking into account the need to conduct scientific research on the crafts, arises the questioning of how handicraft production in large scale relates to the industry and what can be termed industrianato. The research is classified in your nature as basic since it aims to generate new knowledge for the advancement of science without practical application, in relation to the form of qualitative approach, according to its exploratory goals as seen aimed at providing greater familiarity with the problem through a research theoretical and bibliography about crafts and industrianato and based on the concepts studied developed a reflection on the concept of industrianato. The result of the research through the concepts and researches found allowed developing a thought about conceptualization of the existed industrianato showing that it could be extended and better classified. The resulting products of a craft where it is applied the design management under a systemic approach can use or classify the industrianato

Keywords: Design Management, Crafts, Industry, Process innovation.

\section{Referências Bibliográficas}

BELCHIOR, Camilo de Lelis. Reciclando os Sentidos, Ed. Do Autor. Contagem: 2014.

BERTALANFFY, Ludwig Von. Teoria Geral dos Sistemas: fundamentos, Desenvolvimentos e Aplicações, Vozes. Petrópolis: 2010.

BRASIL. Diário Oficial. 06 de Outubro de 2010. Portaria SCS/MDIC N²9.

BORGES, Adélia. Design + Artesanato: 0 caminho Brasileiro. Terceiro Nome. São Paulo: 2011. CARDOSO, Rafael. Uma Introdução à História do Design. Edgard Blucher. São Paulo, 2004.

CHRISTENSEN, C. M. Dilema da inovação: quando novas tecnologias levam empresas ao fracasso. Makron Books. São Paulo: 2001.

DRUCKER, P. Inovação e espírito empreendedor (entrepreneurship): prática e princípios. Pioneira Thomson. São Paulo: 2002.

KRUCKEN, Lia. Design e Território: valorização de identidades e produtos locais. Studio Nobel. São Paulo: 2009.

LANA, S. L. B. A Complexidade dos Métodos em Design. Ed.UEMG. Belo Horizonte: 2011

MARTINS, Rosane Fonseca de Freitas; MERINO, Eugenio A. D. Gestão de Design como Estratégia Organizacional. EDUEL, Rio Books. Londrina: 2011.

MAÑAS, A.V. Gestão de tecnologia e inovação. Érica. São Paulo: 2001.

MASCENE, Durcelice Cândida. Termo de Referência: Atuação do Sistema SEBRAE no Artesanato. Brasília: 2010.

MERINO, G. S. A. D. O Percurso do design: No Ensino e na Prática. Ed. UEMG. Belo Horizonte: 2011

MOZOTA, Brigitte Borja de. Gestão do Design: Usando o Design para Construir Valor de Marca e Inovação Corporativa. Bookman. Porto Alegre: 2011.

MORAIS, Dijon de. Caderno de Estudos Avançados em Design: Design e História. Ed. UEMG. Barbacena: 2014.

MORIN, E. 0 método 1: a natureza da natureza. Tradução de Ilana Heineberg. Sulina. Porto Alegre: 2005.

ROCHA NETO, Ivan. Gestão Estratégica de Conhecimentos \& Competências: Administrando Incertezas e Inovações. UCB/Universa. Brasília: 2003.

RONCALIO, Vanessa weiss. Inovação a Partir do Processo de significação em Produtos: Um Framework Conceitual para o Design. Curitiba: 2015. 
SANTOS, Flávio Anthero dos. O Design como Diferencial Competitivo: o Processo de Design Desenvolvido sob o Enfoque da Qualidade e da Gestão Estratégica. Editora da Univali. Itajaí: 2000.

TRÍAS, de Bes, Fernando. A Bíblia da Inovação. Leya. São Paulo: 2011.

VASCONCELLOS, Maria José Esteves de. Pensamento Sistêmico: O Novo Paradigma da Ciência. Editora Papirus. Campinas: 2013.

ARTIGOS, TESES E DISSERTAÇÕES.

ALANO, Agda Bernadete. Gestão de design como uma Ferramenta Estratégica para Identificar a Inovação Social em uma Comunidade Criativa. Dissertação de Mestrado em Gestão de Design do programa de Pós Graduação em Design da Universidade Federal de Santa Catarina. Florianópolis: 2015

BARBOSA, Ana Carolina de morais Andrade. Cavalcanti, Virginia Pereira. Design, Souvenir e Cultura: Abrangência da Experiência Turística. $12^{\circ}$ P\&D - Congresso Brasileiro de Pesquisa e Desenvolvimento em Design. Outubro 2016/num.2, vol. 9. Belo Horizonte: 2016

DUMONT, Fabiana. Análise do Processo de Comercialização de Produtos Artesanais de Comércio Justo para o Mercado Nacional e Internacional. Dissertação de Mestrado em Gestão do Desenvolvimento Local Sustentável. Faculdade de Ciência da Administração de Pernambuco. Recife: 2015

FREITAS, Ana Luiza Cerqueira, Nicácio, Isadora Mayume Watanabe. O Uso do Mapeamento como Ferramenta de Diagnóstico de Projeto em Design para o Artesanato. $11^{\circ} \mathrm{P} \& D$ - Congresso Brasileiro de Pesquisa e Desenvolvimento em Design. Gramado: 2014

JOHANN, Diane Mere Weiller. Design e Artesanato: Análise da Gestão, Materiais e Técnicas Utilizadas em Grupos de Artesão no Rio Grande do Sul. Dissertação de Mestrado do Programa de Pós Graduação em Design. - UFRGS. Porto Alegre: 2010.

LORETO de Vargas, Daiene. Tecendo Tradições: Artesanato e Mercado Simbólico em uma comunidade Rural do Pampa Gaúcho. Tese de Doutorado do Programa de Pós Graduação em Extensão Rural. Universidade Federal de Santa Maria-UFSM-RS. Santa Maria: 2016.

MAZZA, Adriana Carla Avelino. O Design, a Arte e o Artesanato Deslocando o Centro. Cadernos Ebape. BR, v.05, no 04, Dez.2007. . Ceará: 2007.

RABELO, Livia. O Processo de Expressão da Identidade Local no Artesanato da Associação Municipal de Artesãos de Paula Cândido (AMAPAC). Revista Elo - Dialogo em Extensão. Vol. 4, n.1, Junho de 2015.

SANTANA, Maíra Fontenele. Design e Artesanato: Fragilidades de uma Aproximação. Revista do Centro Interdisciplinar de Desenvolvimento e Gestão Social - CIAGS \& Rede de Pesquisadores em Gestão Social - RGS. vol.3, n.2, jul./ dez. 2012.

SERAFIM, Elisa Feltran. Design e Artesanato: analise de Modelo de Atuação do Design junto a Grupos de Produção Artesanal. Dissertação de Mestrado do Programa de Pós Graduação de Design da UFPE. Recife: 2015.

IUVA de Melo, Carolina. Território Feito à Mão: Artesanato e Identidade territorial no Rio Grande do sul. Tese de Doutorado do Programa de Pós Graduação em Extensão Rural, da UFSM-RS. Santa Maria: 2016.

WANDERLEY, Renata Garcia. Gestão do Conhecimento aplicada a Comunidades Produtivas Artesanais. Tese de Doutorado em Design da Universidade Estadual Paulista Júlio de Mesquita Filho. Bauru: 2015. 